\title{
Cáncer de mama HER2 positivo con metástasis cerebral: reporte de un caso con 76 meses de remisión con capecitabina más lapatinib
}

\author{
- Néstor Eduardo Llinás Quintero, Julián Esteban Londoño Hernández
}

Fundación Colombiana de Cancerología, Clínica Vida, Medellín (Antioquia).

Contacto: nllinas71@gmail.com

Introducción y objetivos. El cáncer de mama HER2 positivo es el principal factor de riesgo para desarrollar metástasis cerebrales. Estas son un reto terapéutico por la alta morbilidad y corta supervivencia asociada. La piedra angular del tratamiento es el control local, seguido de terapia sistémica anti-HER2. Reportamos el caso de una paciente con cáncer de mama HER2 positivo, quien presentó metástasis cerebral 19 meses después del diagnóstico inicial de cáncer.

Materiales y métodos. Se obtuvo consentimiento informado acorde a las buenas prácticas clínicas.

Resultados. La paciente recibió manejo quirúrgico, radioterapia y terapia sistémica con lapatinib + capecitabina, completando a la fecha una supervivencia libre de progresión superior a 72 meses. El tratamiento ha sido ajustado de acuerdo con la tolerancia, manteniendo el control de la enfermedad y la calidad de vida de la paciente.

Conclusiones. Actualmente disponemos de agentes terapéuticos eficaces que mejoran la respuesta clínica e incrementan la supervivencia de estos pacientes.

\section{Resultados de trastuzumab adyuvante en pacientes con cáncer de mama HER2 positivo}

\author{
- Pedro Ramos
}

Oncocare, Bogotá, D.C.

Contacto: pramos152@yahoo.es

Introducción y objetivos. El propósito de este estudio fue evaluar la supervivencia global y libre de enfermedad en pacientes con cáncer de mama HER2 positivo que reciben tratamiento adyuvante con trastuzumab.

Materiales y métodos. En este estudio se hizo el análisis de la información de la clínica Oncocare en el período comprendido entre el $1^{\circ}$ de enero de 2007 hasta el 31 de diciembre de 2014. Se incluyeron todos los pacientes de 18 o más años con diagnóstico de cáncer de mama HER2 positivo que reciben tratamiento adyuvante con trastuzumab. Se construyeron curvas de supervivencia por el método de Kaplan-Meier, se compararon con el método de rangos logaritmos y se realizó un análisis de regresión de rangos proporcionales por Cox.

Resultados. Un total de 121 pacientes fueron identificados en el estudio. La tasa de mortalidad de la cohorte fue del $17,07 \%$ y recaídas del $18,29 \%$. El promedio de edad fue de 53,9 años. El estado clínico fue avanzado en el $54,88 \%$. Los receptores de estrógenos son positivos en el $64,63 \%$ y de progestágeno son positivos en el $45,12 \%$, los ganglios son positivos en el $42,11 \%$. En el análisis multivariado, los factores pronósticos como el estado clínico, el receptor hormonal (positivo), edad y tamaño tumoral no se asocian a tiempos de supervivencia libre de enfermedad y global.

Conclusiones. Los tiempos de supervivencia libre de enfermedad y global no se asocian con factores como edad, receptores hormonales, estado clínico, estado ganglionar, tamaño tumoral y las respuesta objetivas a la quimioterapia neoadyuvante. 